institutes, which are engines for promoting awareness and driving a change in practise within the research communities, are beginning to engage with the issues of reproducibility.

The challenges presented by irreproducibility are vast and seemingly intractable, seeing as they are so entrenched in research practises. The Nature journals have covered the topic of irreproducibility from a variety of perspectives (http://www.nature.com/news/ reproducibility-1.17552). Change will only come about through the concerted effort and engagement of all relevant stakeholders: institutions raising awareness and training students, post-doctoral researchers and principal investigators in best practise, as well as funders and journals implementing efforts to raise reporting standards.

\section{Farewell to our chief}

This year's last issue of Nature Cell Biology is also the last for Sowmya Swaminathan after nearly 13 years at the journal and 6 years as its chief editor. Under Sowmya's able leadership, the journal has evolved both in terms of content and editorial process. Being receptive to the concerns of the scientific community, she has implemented procedures to improve both the author and reader experience. Among these is the limit we now set on supplementary material published with our papers. She has also taken a strong role in facilitating the transfer of manuscripts between the Nature research journals, in particular to Nature Communications, and more recently in developing ways to provide more specific editorial guidance to authors when invited to revise their paper. Sowmya has also been championing the efforts to tackle the issues discussed above regarding data reporting.

Beyond her contributions to the journal, Sowmya has been a fantastic mentor to the Nature Cell Biology editors, always available to provide guidance and support. The team will miss her thoughtfulness, energy and ability to inspire, but looks forward to continue working with Sowmya in her new position as head of editorial policy for the Nature journals, and wishes her all the best in this new role.

We also take this opportunity to welcome our new chief editor, Alexia-Ileana Zaromytidou, who is well known to the cancer, cytoskeleton and cell adhesion and migration communities. 